\title{
Human papillomaviruses and anal cancer
}

In 1793 Benjamin Bell wrote: "I have at present a person who had long been liable to piles, who some time ago was attacked with condylomatous excrescences from a venereal taint; to these succeeded a common abscess from inflammation, and last of all the parts have become cancerous."' During the last few years there has been a renewed interest in the relationship between anal cancer (squamous carcinoma of the anal margin or anal canal) and infection by human papillomaviruses (HPV). Anal cancer is a rare tumour, which in Britain accounts for only $2 \%$ of all anorectal malignancies. ${ }^{2} \mathrm{~A}$ few years ago it was noted that its incidence was higher in single men, and in men who had reactive syphilis serology, than in married men. ${ }^{34}$ This implied, although it did not prove, a relationship between the disease and anal eroticism in male homosexuals. Cases which appeared to support this hypothesis were reported by Cooper $e t$ al, ${ }^{5}$ who had treated four homosexual men with cloacogenic carcinoma, and by Li et al ${ }^{6}$ who described squamous carcinoma of the anus in two homosexual men, one of whom gave a long history of anal condylomas. In a recent epidemiological study Daling et $\mathrm{al}^{7}$ showed that in men a history of anoreceptive intercourse, and of genital warts, were strongly associated with the development of anal cancer. These reports awakened interest in the possibility of an oncogenic potential for HPV at the anus.

In heterosexual men and in women anal warts often accompany genital warts. ${ }^{8}$ Warts confined to the anus and anal canal are commoner in homosexual men, in whom subclinical infections also occur.9 ${ }^{910}$ The presumed mode of transmission of the causal agent is anal intercourse, which is admitted by $80 \%$ of men and women with anal warts, ${ }^{11}$ but in homosexual men these are several times commoner than penile warts. ${ }^{12}$ The reason for this discrepancy is unknown. It may be due to a preferential growth of condylomas in the moist conditions of the anus and anal canal. Alternatively, it has been suggested that the transitional zone, lying between the proximal rectal columnar mucosa and the squamous epithelium of the anal canal, may be analogous to the transitional zone of the cervix uteri, and be a favourable site for HPV infection. ${ }^{13}$ Another possibility is that frequent anal intercourse leads to depressed immune responses which facilitate HPV infection. $^{14}$ Studies of anal condylomas from homosexual men have shown a predominance of HPV 6 and 11 , but sequences of HPV 16 are present in some lesions. ${ }^{15}$

There have been many case reports of anal intraepithelial neoplasia (AIN) Grade 3 (carcinoma in situ) within condylomatous tissue or in anal mucosa adjacent to it, ${ }^{16-19}$ and malignant transformation of perianal condyloma acuminatum and giant condyloma have been described. ${ }^{20-22} \mathrm{Gal}$ et al identified papillomavirus antigens in five of eight squamous carcinomas of the anus from homosexual or bisexual men. ${ }^{23}$ There have been several reports of sequences of HPV 16 in perianal and anal canal cancers. ${ }^{24-26}$ This genotype is often associated with invasive cervical cancer and has been regarded as "high risk"; ${ }^{27}$ however, HPV 16 and 11, so-called "low risk" types, have been identified in a squamous carcinoma of the anus arising in a giant condyloma. ${ }^{22}$

Immunosuppression severely restricts the host's ability to control neoplasms induced by other causes. Penn ${ }^{28}$ has reported a 100 -fold increase in the incidence of carcinoma of the vulva and anus in renal allograft recipients compared with the general population. Warts, including anogenital warts, are also common in these patients. ${ }^{29}$ Anogenital warts develop in many homosexual men with human immunodeficiency virus (HIV) infection. ${ }^{30}{ }^{31}$ Frazer et $_{\text {al }}{ }^{13}$ reported a high incidence of cytological changes suggesting both HPV infection and dysplasia of the anorectal epithelium among homosexual men with HIV infection and evidence of immune dysfunction (a low CD4/CD8 ratio). Croxson et al ${ }^{17}$ described seven homosexual men with carcinoma in situ associated with anal warts, four of whom had AIDS-related symptoms, and Howard et $\mathrm{al}^{32}$ described two cases of carcinoma of the anus in homosexual HIV-positive men with T-helper lymphocyte depletion, one of whom gave a long history of perianal warts.

How are the data relating homosexuality, HPV infection and anal neoplasia to be interpreted? Comparisons between the aetiology of carcinoma of the anus and carcinoma of the cervix should be made with caution. The epidemiological evidence implicating specific HPV types as a cause of cervical neoplasia has recently been criticised by Munoz et $a l^{33}$ on the 
grounds of small sample size, potentially biased selection of study subjects and the unknown sensitivity and specificity of the various hybridisation procedures for detecting DNA. Moreover, earlier studies have consistently underestimated the prevalence of HPV 16 in the normal cervix. Recent use of the polymerase chain reaction has shown that HPV 16 DNA is present in $80 \%$ of women with normal cytology; $;^{34}$ clearly the relationship between HPV and cervical cancer is not as straightforward as it appeared to be a few years ago. ${ }^{35}$ These observations apply with equal force to the problems surrounding anal neoplasia. We know very little about the epidemiology of anal HPV infection. The prevalence of infection of normal anal epithelia with HPV genotypes is unknown. Although HPV 16 has been identified in anal neoplasms the number of cases has been small and the studies either poorly controlled or not controlled at all. The most appropriate method of detecting HPV in anal specimens has not yet been decided. If specific HPV types are involved in anal neoplasia they would almost certainly be as necessary rather than sufficient causes; other factors, such as trauma, infection, antigen load and the subject's immune status are likely to be involved.

There is a real need for more studies of anal HPV infection and its relationship to neoplasia. These should include: (1) data on the prevalence of HPV genotypes in normal anal epithelia in homosexual and heterosexual men, (2) reassessment of the natural history of uncomplicated HPV infection in relation to clinical and subclinical lesions and infecting genotypes, (3) well designed case-control studies of the frequency of HPV genotypes in men with AIN and anal cancer, (4) prospective cohort studies of men with clinical and subclinical anal HPV infection, and (5) assessment of the results of treatment of HPVassociated lesions of the anus in patients with and without impaired immunity. Some of these problems are addressed in articles in this issue of Genitourinary Medicine. Syrjanen, Von Krogh and Syrjanen (p 216) have studied a series of condylomas obtained from homosexual and heterosexual men, seeking associations between their sexual orientation, their HIV status, the duration and morphology of the warts, the HPV types present and the degree of AIN observed. In most cases overt wart disease was associated with HPV 6 and 11; the "high risk" types HPV 16, 18, 31 and 33 were uncommon. AIN I-II was present in about $30 \%$ of lesions, but was not associated with any specific genotypes. McMillan and Bishop (p 225) studied the effect of HIV infection on the natural history of anogenital warts in men. Particularly in homosexuals, HIV infection was associated with a prolonged duration of the warts both before and after the initiation of treatment. Anal malignancy was not detected in any of the patients in this series, but in view of the current uncertainty about the long-term effects of HPV infection, the authors are surely right to advocate regular examination of HIV-infected patients for early neoplasia of the anus and anal canal.

J D ORIEL

\section{References}

1 Bell B. A Treatise on Gonorrhoea Virulenta and Lues Venerea. Edinburgh: Watson, Mudie and Murray, 1973; vol 2:100.

2 Office of Population Censuses and Surveys. 1984 Cancer statistic registration. London: HMSO, 1988:42. (Series MB1, No 16.)

3 Daling JR, Weiss NS, Klopfenstein LL, et al. Correlates of homosexual behaviour and the incidence of anal cancer. JAMA 1982;247:1988-90.

4 Peters RK, Mack TM. Patterns of anal carcinoma by gender and marital status in Los Angeles County. Br J Cancer 1983;48: 629-36.

5 Cooper HS, Patchefsky AS, Marks G. Cloacogenic carcinoma of the anorectum in homosexual men: an observation of four cases. Dis Colon Rectum 1979;22:557-8.

$6 \mathrm{Li} \mathrm{FP,} \mathrm{Osborn} \mathrm{D,} \mathrm{Cronin} \mathrm{CM.} \mathrm{Anorectal} \mathrm{squamous} \mathrm{carcinoma} \mathrm{in}$ two homosexual men. Lancet 1982;ii:391.

7 Daling JR, Weiss NS, Hislop TG, et al. Sexual practices, sexually transmitted diseases, and the incidence of anal cancer. $N$ Engl $J$ Med 1987;317:973-7.

8 Goorney BP, Waugh MA, Clarke J. Anal warts in heterosexual men. Genitourin Med 1987;63:216.

9 Medley G. Anal smear test to diagnose occult anorectal infection with human papillomavirus in men. Br J Vener Dis 1984;60:205.

10 Carr G, William DC. Anal warts in a population of gay men in New York City. Sex Transm Dis 1977;4:56-7.

11 Oriel JD. Anal warts and anal coitus. Br J Vener Dis 1971;47: 373-6.

12 Judson FN, Penley KA, Robinson ME, Smith JK. Comparative prevalence rates of sexually transmitted diseases in heterosexual and homosexual men. Am J Epidemiol 1980;112:836-43.

13 Frazer IH, Medley G, Crapper RM, Brown TC, Mackay IR. Association between anorectal dysplasia, human papillomavirus and human immunodeficiency virus in homosexual men. Lancet 1986;ii:657-60.

14 Detels R, Fahey JL, Schwartz K, Greene RS, Visscher BR, Gottlieb MS. Relation between sexual practices and T-cell subsets in homosexually active men. Lancet 1983;i:609-11.

15 McCance DJ, Lowe D, Simmons P, Thomson JPS. Human papilloma virus in condylomata acuminata of the anus. J Clin Pathol 1986;39:927.

16 Oriel JD, Whimster I. Carcinoma in situ associated with viruscontaining anal warts. Br J Dermatol 1971;84:71-3.

17 Croxson T, Chabon AB, Rorat E, Barash IM. Intraepithelial carcinoma of the anus in homosexual men. Dis Colon Rectum 1984;27:325-30.

18 Nash G, Allen W, Nash S. Atypical lesions of the anal mucosa in homosexual men. JAMA 1986;256:873-6.

19 Fiumara NJ, Wagner RF. Perianal Bowen's disease associated with anorectal warts: a case report. Sex Transm Dis 1987;14: 58-60.

20 Lee SH, McGregor DH, Kuziez MN. Malignant transformation of perianal condyloma acuminatum. Dis Colon Rect 1981; 24:462-7.

21 Ejeckam GC, Idikio HA, Nayak V, Gardiner JP. Malignant transformation in an anal condyloma acuminatum. Can J Surg 1983;26:170-3.

22 Wells M, Robertson S, Lewis F, Dixon MF. Squamous carcinoma arising in a giant peri-anal condyloma associated with human papillomavirus types 6 and 11. Histopathol 1988;12:319-23.

23 Gal AA, Meyer PR, Taylor CR. Papillomavirus antigens in anorectal condyloma and carcinoma in homosexual men. JAMA 1987;257:337-40. 
24 Hill SA, Coghill SB. Human papillomavirus in squamous carcinoma of the anus. Lancet 1986;ii:1333.

25 Wells M, Griffiths S, Lewis F, Bird CC. Demonstration of human papillomavirus types in paraffin processed tissue from human anogenital lesions by in situ DNA hybridisation. J Pathol 1987; 152:77-82.

26 Palmer JG, Shepherd NA, Jass JR, Crawford LV, Northover JMA. Human papillomavirus type 16 DNA in anal squamous cell carcinoma. Lancet 1987;ii:42.

27 Howley PM. On human papillomaviruses. $N$ Engl J Med 1986;315: 1089-90.

28 Penn I. Cancers of the anogenital region in renal transplant recipients. Cancer 1986;58:611-6.

29 Koranda FC, Dehmel EM, Kahn G, Penn I. Cutaneous complications in immunosuppressed renal homograft recipients. JAMA 1974;229:419-24.

30 Evans BA, Dawson SG, McLean KA, et al. Sexual lifestyle and clinical findings related to HTLV III/LAV status in homosexual men. Genitourin Med 1986;62:384-9.

31 Rudlinger R, Grob R, Buchmann P, Christen D, Steiner R. Anogenital warts of the condyloma acuminatum type in HIV positive patients. Dermatologica 1988;176:277-81.

32 Howard LC, Paterson-Brown S, Weber JN, Chan STF, Harris JRW, Glazer G. Squamous carcinoma of the anus in young homosexual men with T helper cell depletion. Genitourin Med 1986;62:393-5.

33 Munoz N, Bosch X, Kaldor JM. Does papillomavirus cause cervical cancer? The state of the epidemiological evidence. $\mathrm{Br} J$ Cancer 1988;57:1-5.

34 Tidy JÀ, Parry GCN, Ward P, et al. High rate of human papillomavirus type 16 infection in cytologically normal cervices. Lancet 1989;i:434.

35 Leading article. Human papillomaviruses and the polymerase chain reaction. Lancet 1989;1:1051-2. 